\title{
Self-weight Balance Design of Portal Crane Boom
}

\author{
Yi Huang ${ }^{1, a}$, and Haixia Zeng ${ }^{1, b^{*}}$,and Yan Chen ${ }^{1, c}$ \\ ${ }^{1}$ Mechanical \& Electronic Engineering Division, WenHua College, Wuhan, Hubei, 430074, China
}

\begin{abstract}
During the luffing of the portal crane, the height changing of the center of gravity of the boom needs to consume extra energy, which not only wastes energy, but also makes the luffing drive system need to use a larger motor. This paper uses the lever-movable counterweight balance method to design the self-weight balance of the portal crane, and verifies that the designed jib self-weight balance system meets the requirements of the maximum height deviation, unbalanced torque and comprehensive unbalanced torque by evenly taking points. The power and unnecessary energy consumption of the luffing drive mechanism are reduced.
\end{abstract}

\section{Introduction}

Portal cranes use boom pitching to lift goods within a certain range. This process is called luffing process. The boom pitching will change the height of the boom's own center of gravity, which requires additional energy consumption. In order to ensure that the height of the center of gravity of the boom system does not change as much as possible during the luffing process of the crane, so as to reduce the power consumption of the luffing drive due to the need to do work for the lifting of the center of gravity, the method of self-weight balance of the boom is usually used to make sure that the synthetic center of gravity of the boom system won't move during the luffing process or will move along a horizontal line or a trajectory close to the horizontal line.

\section{Boom self-weight balance methods and analyses}

\subsection{Constant center of gravity balance method}

The constant center of gravity balance method is to use the movable counterweight to make the synthetic center of gravity of the boom system fixed during the luffing process. Its working principle is to directly arrange the movable counterweight on the extension line connecting the boom center of gravity and the boom hinge axis, and ensure the synthetic center of gravity of the boom and the counterweight exactly at the center of the boom hinge axis [1].

The method has a simple structure and can ensure that the boom can achieve complete self-weight balance at any position. However, the length of the counterweight boom is limited by the overall layout of the crane, and cannot be too large. Therefore, the weight of the counterweight is required to be large, so that the weight of the counterweight is aligned. Thus the stability of the machine and the balance of the rotating part are restricted.

\subsection{Non-counterweight balance method}

The non-counterweight balance method relies on the structural characteristics of the boom system itself, so that the boom system's synthetic center of gravity moves along the horizontal track during the luffing process. The working principle is that the lower hinge point of the boom can move up and down along the vertical guide rail. Using the principle of ellipse gauge, the boom system's synthetic center of gravity can be moved along the horizontal track through appropriate structural size design [2].

The advantage of the non-counterweight balance method is that it does not need to balance the counterweight, but the boom is under unfavorable force and the structure is more complicated. To meet the stability requirements of the whole crane, it is often necessary to increase the weight.

\subsection{Movable center of gravity balance method}

The movable center of gravity balance method is to connect the boom and the movable counterweight by a lever system or flexible member, so that the boom' $\mathrm{s}$ synthetic center of gravity and its balance system moves along an approximate horizontal track during the luffing process. In the portal crane design, the typical moving center of gravity balance method is the Lever-Movable counterweight Balance Method [3].

The design principle is to make the torque of the boom's own weight to the lower hinge point of the boom 
as equal as possible to the torque of the movable counterweight to the hinge point. Using the reasonable design of the lever ratio, the swing angle of the movable counterweight can be significantly increased on the premise that the swing angle of the boom remains unchanged, which provides the possibility to further reduce the dead weight of the counterweight; and the counterweight is far away from the boom and lifted high, which is conducive to the overall layout and can play the role of counterweight on the stability of the whole machine. This kind of balance scheme is currently widely used. The disadvantage is that it is difficult to achieve a complete balance in the full range of the scheme. However, through a reasonable design, the error can be reduced to a small extent to meet actual requirements [4].

In summary, the lever-movable counterweight balance method has obvious advantages in the self-weight balance design of the portal crane boom, so this article uses this method for design.

\section{Design method and process}

\subsection{Initial data}

The initial data is shown in Table 1.

Table 1 Initial data

\begin{tabular}{|c|c|}
\hline Maximum amplitude & $R_{\max }=33 m$ \\
\hline Minimum amplitude & $R_{\min }=11 m$ \\
\hline Maximum elevation angle & $\alpha_{\max }=74.5^{\circ}$ \\
\hline Minimum elevation angle & $\alpha_{\min }=25^{\circ}$ \\
\hline Lifting weight & $Q=16 t$ \\
\hline $\begin{array}{c}\text { Wire rope force of } \\
\text { compensation pulley group }\end{array}$ & $S=2.5 Q=40 t$ \\
\hline Boom length & $L=34.4 m$ \\
\hline $\begin{array}{c}\text { Magnification of lifting } \\
\text { pulley block }\end{array}$ & $m_{q}=2$ \\
\hline $\begin{array}{c}\text { Magnification of } \\
\text { compensation pulley block }\end{array}$ & $m_{b}=2.5 m_{q}=5$ \\
\hline $\begin{array}{c}\text { Boom weight } \\
G_{b}=28 t\end{array}$ \\
\hline
\end{tabular}

\subsection{Determine the geometric dimensions and weight of the movable counterweight}

First, determine the position of the lever fulcrum and the swing radius of the movable counterweight according to the overall layout requirements, and then initially determine the connection point of the small pull rod and the boom according to the boom structure requirements, and finally use the drawing method to work out the size of the lever, length of the connecting rod and the weight of the counterweight.

Draw after determining the position of the compensation point $\mathrm{O} 1$ and the relative size, as shown in Figure 1 .

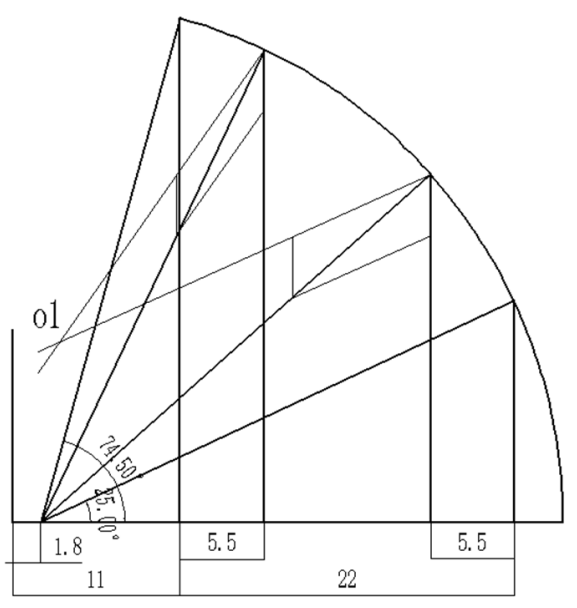

Figure 1 Diagram of determining compensation points and related dimensions

According to the principle that the increased potential energy of the boom's self-gravity center from the maximum amplitude to the minimum amplitude is equal to the reduced potential energy of the counterweight falling:

Movable counterweight weight:

$$
G_{d}=G_{b} \cdot h_{2} / h_{2}^{\prime}=28 \times 6.2 / 9.18=18.91 t
$$

Counterweight position at the middle amplitude:

$$
h_{1}^{\prime}=G_{b} / G_{d} \cdot h_{1}=28 / 18.91 \times 3.94=5.83 m
$$

Take 10 points uniformly on the luffing length, and calculate the self-gravity torque of the boom and the movable counterweight torque for the position of each point. The schematic diagram of taking points is shown in Figure 2.

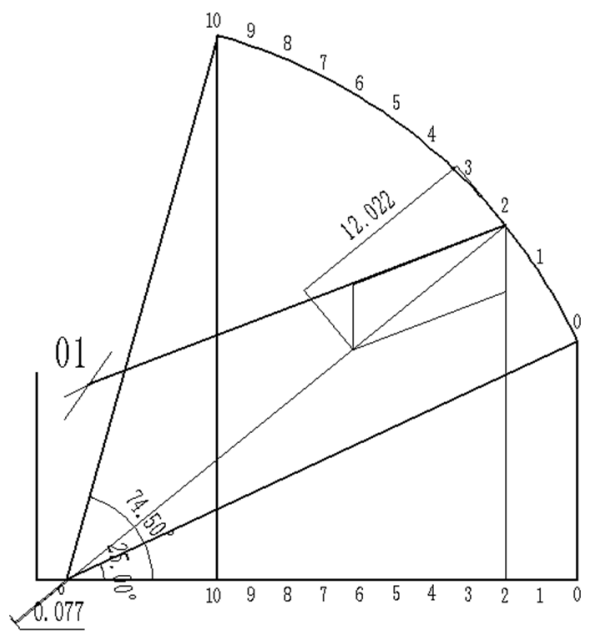

Figure 2 Schematic diagram of taking points

Then according to the design principle and drawing method, the connection point of the counterweight system and the small pull rod is determined, so as to determine the size of the front section of the balance beam and the length of the small pull rod. The solution diagram is shown in Figure 3. 


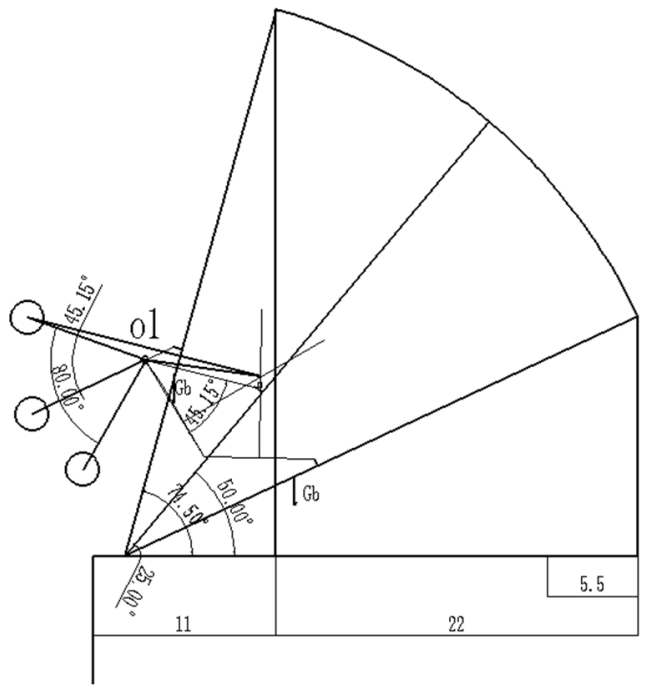

Figure 3 Schematic diagram of solving the dimensions of the front section of the balance beam and the length of the small pull rod

\section{System performance verification}

\subsection{Calibration of the height difference of the compensation system hoisting horizontal displacement.}

The following data can be obtained by mapping and analyzing the 10 points evenly taken:

The changes of the center distance of the compensation pulley:

$$
\Delta l=\left[\begin{array}{l}
1.526 \\
2.725 \\
3.714 \\
4.547 \\
5.253 \\
5.848 \\
6.343 \\
6.746 \\
7.061 \\
7.294
\end{array}\right] m
$$

The height changes of boom head:

$$
\Delta h=\left[\begin{array}{c}
4.001 \\
7.058 \\
9.533 \\
11.592 \\
13.327 \\
14.796 \\
16.037 \\
17.076 \\
17.934 \\
18.624
\end{array}\right] m
$$
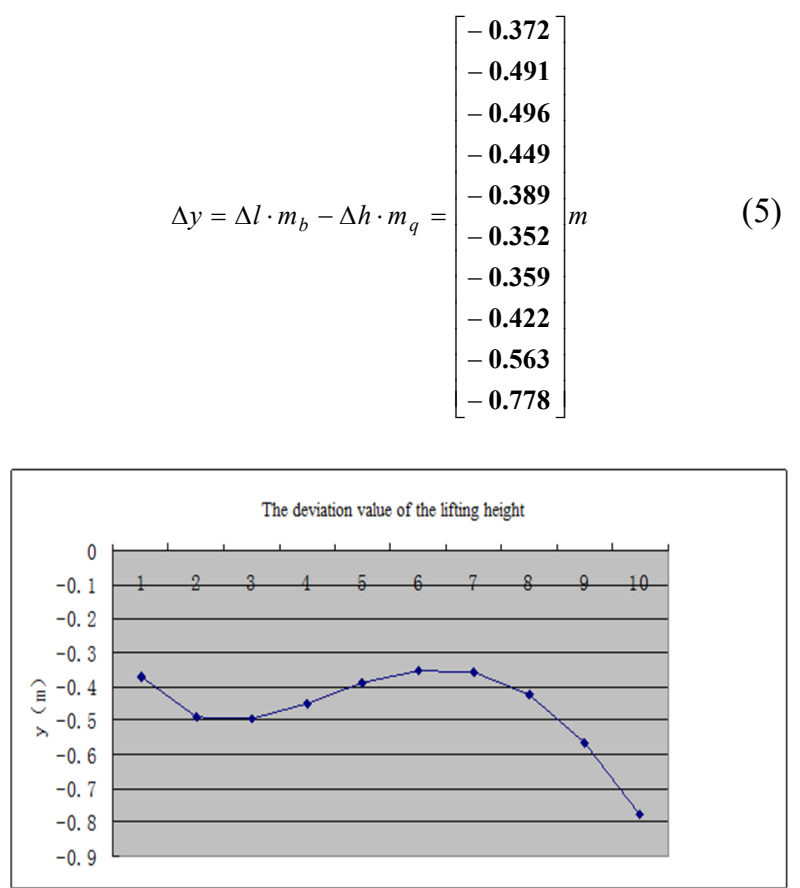

Figure 4 The deviation value of the lifting height of each point in the same range

The hoisting height deviation value of each point of the amplitude equalization is shown in Figure 4, and its maximum value satisfies:

$$
\Delta y_{\max }=\left|\Delta y_{\max }-\Delta y_{\min }\right|=0.426 m \leq 0.03\left(R_{\max }-R_{\min }\right)=0.66 m(6)
$$

\subsection{Calibration of boom balance system}

The gravity torque of the boom system's own weight to the lower hinge point $\mathrm{O}$ of the boom (clockwise is positive):

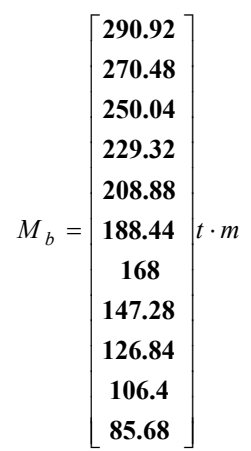

The converted gravitational torque of the movable counterweight to the lower hinge point $\mathrm{O}$ of the boom: 


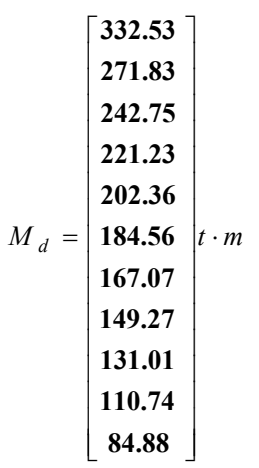

The unbalanced torque caused by the gravity of the boom and its balance system:
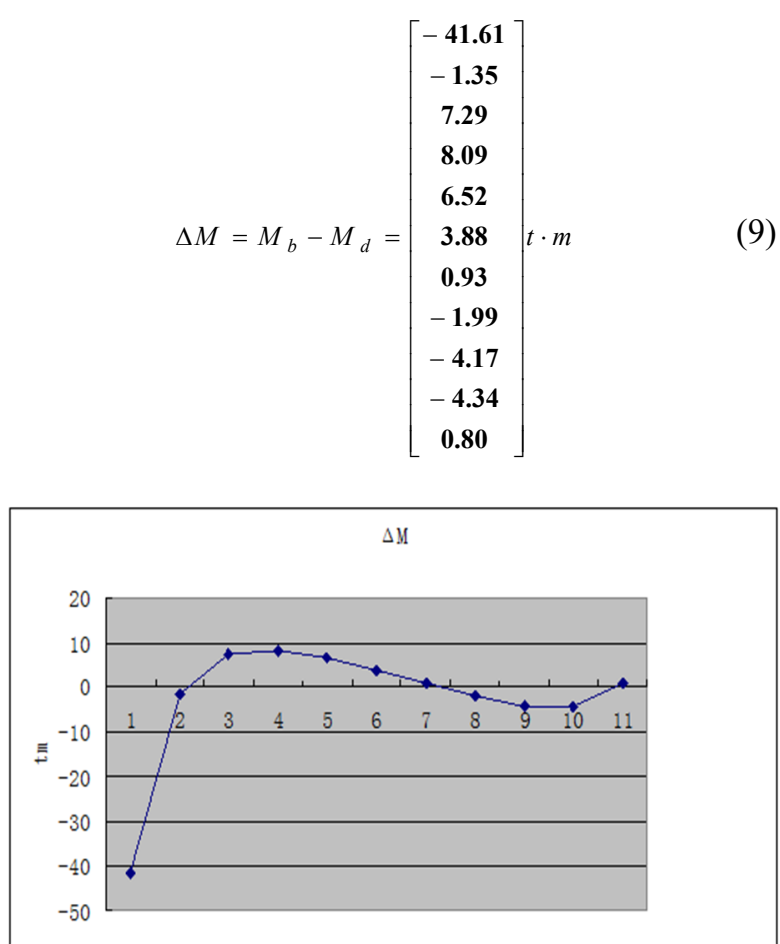

Figure 5 Unbalanced torque caused by the gravity of the boom and its balance system

The unbalanced torque caused by the gravity of the boom and its balance system is shown in Figure 5. Its maximum value satisfies $[5,6]$ :

$$
\left|\Delta M_{\max }\right|=41.61 t \cdot m \leq 0.1 M_{Q}=0.1 Q \cdot R_{\max }=52.8 t \cdot m(10)
$$

Unbalanced torque of lifting weight to the lower hinge point $\mathrm{O}$ of the boom:

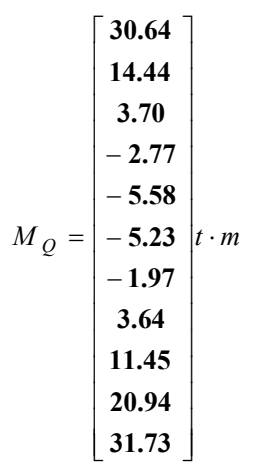

The comprehensive unbalanced torque is:
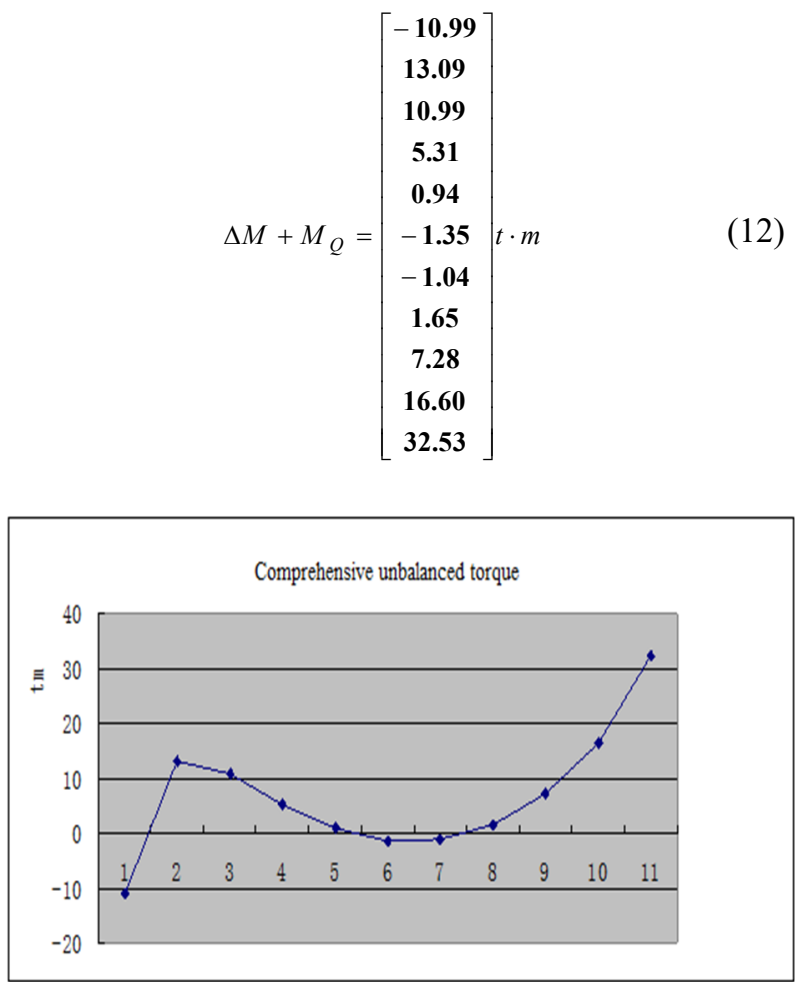

Figure 6 Comprehensive unbalanced torque

The comprehensive unbalanced torque is shown in Figure 6.

At maximum amplitude $[5,6]$ :

$$
\begin{aligned}
\Delta M & =-41.61 t \cdot m \prec 0 \\
\Delta M+M_{Q} & =-41.61+30.62=-10.99 t \cdot m \prec 0
\end{aligned}
$$

At minimum amplitude $[5,6]$ :

$$
\begin{gathered}
\Delta M=0.80 t \cdot m \succ 0 \\
\Delta M+M_{Q}=0.80+31.73=32.53 t \cdot m \succ 0
\end{gathered}
$$

In summary, the designed boom balance system meets the requirements.

\section{Summary}

In the design process, through repeated tests and 
calculations on the lever fulcrum and various dimensions, a solution that meets the design requirements was finally found. With this system, the portal crane can maintain the synthetic center of gravity of the boom and the movable counterweight system approximately on a horizontal straight line during the luffing process, thereby reducing the power of the luffing drive mechanism and unnecessary energy consumption and making a small contribution to the national carbon peak and carbon neutral goals in the subtleties.

\section{References:}

1. Guo Y, Yan B. (2013) Port Hoisting Machinery. Wuhan University of Technology Press, Wuhan .

2. Jiang GR. (1995) Port Hoisting Machinery. Dalian Maritime University Press,Dalian.

3. Li GY.(2004) Port Hoisting Machinery. People's Communications Press, Beijing.

4. Ni QX, Wang HY. (1990) Port Hoisting Machinery. Shanghai Jiaotong University Press,Shanghai .

5. Zhang ZW. (1997) Crane Design Manual.China Railway Press,Beijing.

6. Code for design of cranes(GB/T 3811-2008). China Standard Press, Beijing. 